\title{
Thiopurine Metabolite Testing in Inflammatory Bowel Disease
}

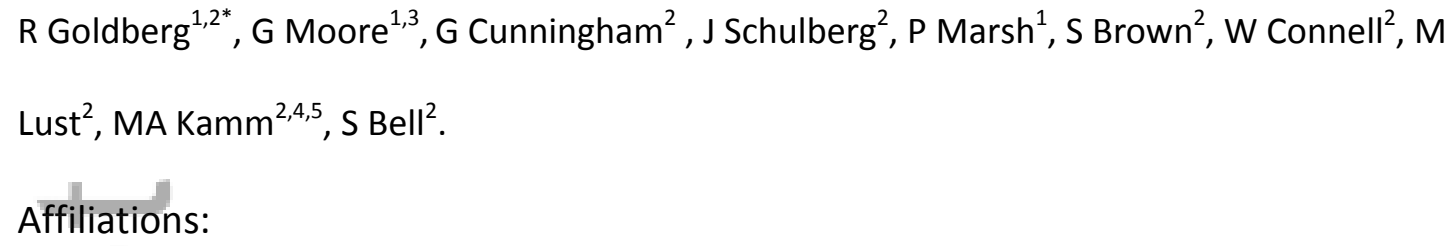

1. Monash Health, Melbourne, Australia

2. St Vincent's Hospital, Melbourne, Australia

3. Centre for Inflammatory Diseases, Southern Clinical School, Monash

4. University of Melbourne, Australia

5. Imperial College London, UK

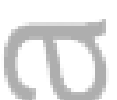

*Correspondence to: rimmagoldberg@gmail.com
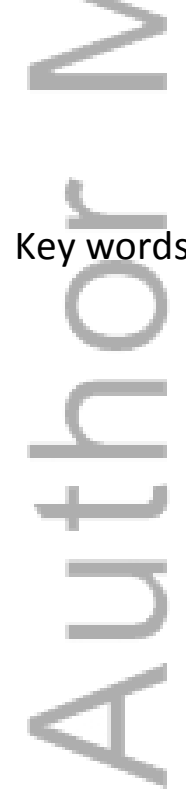

This is the author manuscript accepted for publication and has undergone full peer review but has not been through the copyediting, typesetting, pagination and proofreading process, which may lead to differences between this version and the Version of Record. Please cite this article as doi: $10.1111 /$ jgh. 13210

This article is protected by copyright. All rights reserved. 


\section{Abstract}

\section{Background}

Thiopurines use in inflammatory bowel disease (IBD) is limited by drug toxicity and lack of therapeutic efficacy. We assessed the utility of thiopurine metabolite testing and the relationship between disease activity, dose and metabolite levels in a real world setting.

\section{Methods}

Patients identified from pathology databases (2007-2012) at 2 tertiary IBD centers were included if they had thiopurines for at least four weeks. Demographics, dose, test indication, clinical status, action taken, and outcome were obtained by retrospective medical record review.

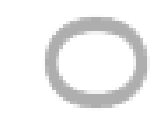

\section{Results}

169 patients were included. TGN levels were sub-therapeutic in 52\%, therapeutic in $34 \%$, and supratherapeutic in $14 \%$. Test indication was active disease $(79 \%)$, adverse effect (11\%), or adherence assessment (7\%). TGN trended lower in the active disease group compared to those with adverse effects $(273(+/-23.2)$ vs $447(+/-117.7)$ 
$\left.\mathrm{pmol} / 8 \times 10^{8} \mathrm{RBC}, \mathrm{p}=0.05\right)$. Weight based dosing did not improve rates of therapeutic TGN levels (under-dosed $31.5 \%$ vs standard dose $35.4 \%$ ), however was significantly associated with shunting towards $6-\mathrm{MMP}(23.1 \%$ vs $6.8 \%, p=0.008$, $\mathrm{OR}=4.1$ ). Testing resulted in a change in patient treatment in $86 \%$ of patients with active disease and subtherapeutic levels and in $68 \%$ of tested patients overall.

\section{Conclusions}

Metabolite testing resulted in a change in management in most patients not responding to thiopurines or experiencing adverse events. Weight based dosing did not increase rates of therapeutic levels however was associated with increased 6MMP shunting.

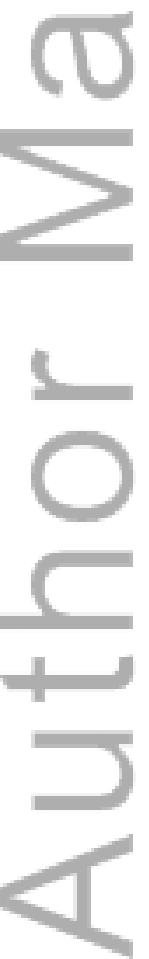

This article is protected by copyright. All rights reserved. 


\section{$\ddot{\circ}$ \\ (1) \\ () \\ Background}

Thiopurines are effective in paediatric and adult Inflammatory Bowel Diseases (IBD), and are increasingly used early in the disease course to attempt to alter the natural history of these conditions. However drug toxicity leads to the cessation of therapy in $9-25 \%$ of cases. ${ }^{1}$ Some studies, such as the Study of Biologic and Immunomodulator Naive Patients in Crohn's Disease (SONIC) study, which compared azathioprine, infliximab and combination therapy, have suggested that treatment efficacy may be limited, with $70 \%$ of patients on azathioprine alone failing to achieve remission at 26 weeks in that study ${ }^{2}$. The contributing factors to lack of efficacy may be low 6-thioguanine (TGN) metabolite levels due to poor adherence, inadequate dosing, preferential metabolism toward the alternative 6-methyl mercaptopurine (6MMP shunting) or thiopurine-refractory disease. ${ }^{3}$ 
Traditionally, thiopurine dosing has been weight based - typically $2.0-2.5 \mathrm{mg} / \mathrm{kg} / \mathrm{day}$ of azathioprine $\mathrm{e}^{3,4,5}$ or $1.0-1.5 \mathrm{mg} / \mathrm{kg} /$ day of mercaptopurine ${ }^{19}$. Although thiopurine metabolite testing is used increasingly it is unclear whether altering the dose to achieve a "therapeutic" level improves the clinical response, although a cross sectional study did correlate clinical efficacy and side effects with metabolite levels. $1,6,7,8,9,10,11$

in

Azathioprine is a pro-drug that is converted non-enzymatically to 6-mercaptopurine (mercaptopurine). Its metabolism to therapeutic and toxic metabolites is outlined in the diagram below.

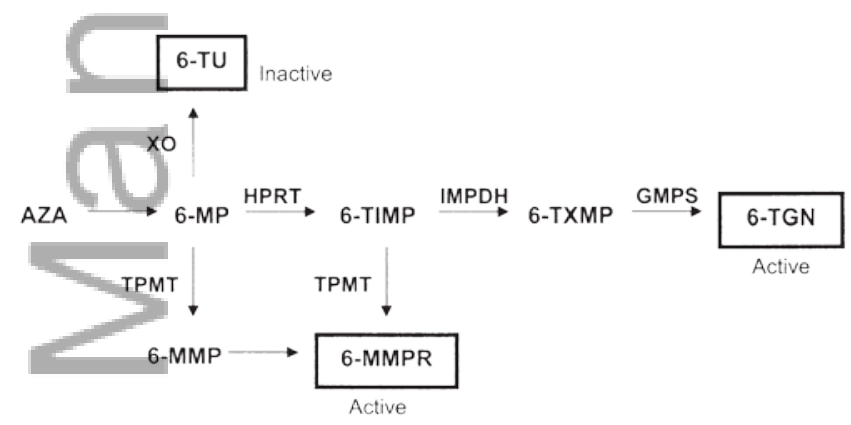

6-thioguanine nucleotides accumulate in tissues where they are thought to exert their cytotoxic effects by inhibition of purine synthesis and ultimately DNA and RNA synthesis. Azathioprine and mercaptopurine also inhibit the proliferation of $\mathrm{T}$ and $\mathrm{B}$ lymphocytes, leading to decreased production of cytotoxic T lymphocytes and plasma cells. They also lead to apoptosis of T-cells ${ }^{12} \cdot 6$-thioguanine is an alternative therapy that avoids the thiopurine-S-methyltransferase (TPMT) metabolic pathway to 6MMP and TGN and instead is metabolized by TPMT to S-methyl-thioguanine, the 
biologic effects of which are not fully understood ${ }^{13,14}$. Subsequently, concerns regarding hepatotoxicity with nodular regenerative hyperplasia have limited the use of thioguanine. $^{15}$

Assays for TGN and 6-MMP are now widely available. Levels of TGN between 235 and $450 \mathrm{pmol} / 8 \times 10^{8}$ erythrocytes (red blood cells (RBC)) have been found to correlate with therapeutic response while 6-MMP levels greater than 5700

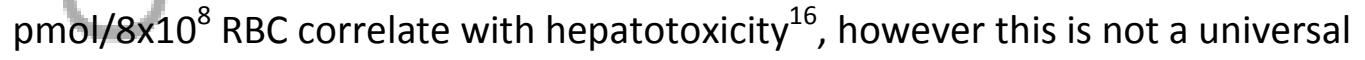
correlation and patients can develop hepatotoxicity in the presence of normal 6MMP levels. Some patients preferentially metabolize thiopurines towards 6MMP resulting in low TGN levels. Allopurinol is a purine analogue that competes with xanthine oxidase, redirecting metabolism away from 6-MMP production, resulting in increased levels of TGN. Co-treatment with allopurinol also results in production of thioxanthine and subsequent direct inhibition of TPMT ${ }^{17}$.The addition of allopurinol may correct an unfavorable ratio of TGN to 6-MMP by reducing 6-MMP concentrations and increasing TGN concentrations ${ }^{18,19}$.

Recent studies have suggested that a dosing strategy based on TPMT and thiopurine metabolite testing is cost effective ${ }^{20}$ but relatively underutilized by gastroenterologists world wide. ${ }^{21}$ 
The aim of this study was to evaluate the clinical utility of this assay in a real world setting and its potential to alter patient outcomes.

\section{Materials and Methods}

All patients who had undergone thiopurine metabolite testing between January

2007 to November 2012 at two tertiary IBD care hospitals were identified from pathology databases. These were cross-referenced with patient files. Patients were then included if they had been tested in the context of IBD, and had been taking a thiopurine for at least four weeks.

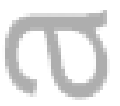

Medical records of all hospital patients were identified and clinical data were retrieved from the time of thiopurine metabolite testing as well as at the time of any further tests. Demographic data, reason for testing, clinical status at the time of testing (based on physician global assessment - a score of 1-6 based on whether patient had complete relief of symptoms (1) to worsening of symptoms (6), blood tests, imaging and endoscopy findings), action taken in response to test result (change in dose, change of therapy or no action), and outcome (physician global assessment of disease activity at 6 months), were determined. For patients treated 
in outside clinics the above information was obtained via a survey sent out to the treating gastroenterologist.

Thiopurine metabolite levels were assayed using the Dervieux-Boulieu method ${ }^{22}$ Therapeutic TGN levels were defined as 235-450 pmol/8 x 10 RBC, "acceptable" 6MMP levels defined as $<5700 \mathrm{pmol} / 8 \times 10^{8} \mathrm{RBC}$, and "acceptable" 6MMP:TGN ratio was defined as $<20 .{ }^{1}$ Shunting of 6-MP toward the production of 6-MMP with inadequate levels of TGN, was defined by a 6MMP:TGN ratio $>20 .^{9,8}$ Standard dose was defined as $2.0 \mathrm{mg} / \mathrm{kg} /$ day for azathioprine and $1.5 \mathrm{mg} / \mathrm{kg} /$ day for mercaptopurine. ${ }^{23}$ This azathioprine dose, at the lower end of the recommended starting dose range, reflects the common practice of local practitioners.

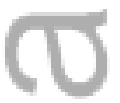

\section{Statistic Analysis}

All values were assessed for normality using the d'Agostino-Pearson omnibus normality test. Continuous variables were analysed using Mann Whitney testing and categorical variables analysed using Chi Squared or Fisher's exact testing where appropriate. Spearman's test was used for correlation. Standard ranges provided by testing laboratory were used in the study. Values are expressed as mean or median +/-standard error of the mean.

\section{Ethics Approval}

This article is protected by copyright. All rights reserved. 
Ethics approval was obtained from St Vincent's Hospital Clinical Governance Unit Ref: QA: 074/12.

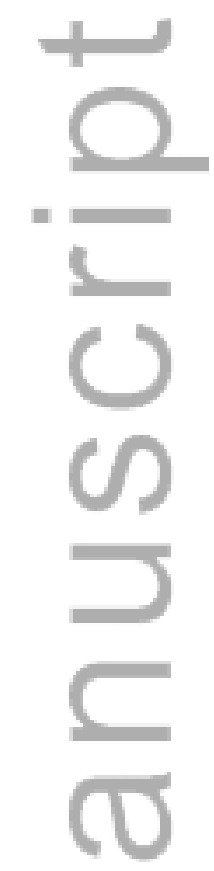

Results

A total of 169 patients with thiopurine metabolite testing were identified, of whom 146 had body weight data available. Mean age was 34 years (range 14-82). Seventy eight (46\%) were female. 69\% had Crohn's disease, $26 \%$ had Ulcerative Colitis, and 5\% IBD-unspecified (IBD-U). 63\% patients were from hospital outpatient clinics and $37 \%$ were from private gastroenterologist clinics.

This article is protected by copyright. All rights reserved. 
$79 \%$ of tests were performed due to active disease, $11 \%$ due to adverse effects, $7 \%$ to check compliance and 4\% for another reason. 124 (73\%) patients were on azathioprine (mean dose $2.0(+/-0.06) \mathrm{mg} / \mathrm{kg} /$ day) and $45(27 \%)$ on mercaptopurine (mean dose $1.0(+/-0.09) \mathrm{mg} / \mathrm{kg} /$ day).

Overall, 57 (34\%) patients of the 169 analysed had therapeutic TGN levels, and of these $9(5 \%)$ preferentially metabolized to 6-MMP. Eighty-eight (52\%) patients had subtherapeutic TGN levels (of whom 7 (8\%) had a metabolic profile favoring 6-MMP production), while 24 (14\%) had supratherapeutic levels (all of whom had a standard metabolic profile).

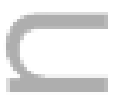

Patients with active disease trended to having a lower TGN levels compared to those tested for adverse effects, with median TGN of $232(0-1596) \mathrm{pmol} / 8 \times 10^{8} \mathrm{RBC}$ and $287(148-1596) \mathrm{pmol} / 8 \times 10^{8} \mathrm{RBC}$ respectively $(p=0.02)$. There was no significant difference in 6-MMP levels between the group tested for active disease compared with those tested due to adverse effects (median 1293 (0-16623) pmol/8 $\times 10^{8}$ RBC vs $1052(0-18000) \mathrm{pmol} / 8 \times 10^{8} \mathrm{RBC}(\mathrm{p}=0.70)$. There was also no significant difference in the rates of $6 \mathrm{MMP}$ shunting between the two groups: $15 \%$ vs $18 \%, p=$ 0.76. (Table 1)

This article is protected by copyright. All rights reserved. 
The results for patients receiving either azathioprine or mercaptopurine were combined and analysed by weight based dosing dose $(\mathrm{mg} / \mathrm{kg} /$ day), divided into low dose ( $<2.0 \mathrm{mg} / \mathrm{kg} /$ day azathioprine, $<1.5 \mathrm{mg} / \mathrm{kg} /$ day mercaptopurine respectively), or standard dose $(\geq 2.0 \mathrm{mg} / \mathrm{kg} /$ day azathioprine, $\geq 1.5 \mathrm{mg} / \mathrm{kg} /$ day mercaptopurine respectively). Low dosing did not predict sub therapeutic TGN levels ( $57.5 \%$ vs $46.2 \%, p=0.49)$. Similarly, standard dosing was not predictive of therapeutic $(31.5 \%$ vs $35.4 \% p=0.7)$ or supratherapeutic TGN levels $(11.0 \%$ vs $18.5 \% p=0.23)$ when compared to the low dose group. In this combined group, there was no significant correlation between the $\mathrm{mg} / \mathrm{kg} /$ day dose and the TGN levels $(r=0.14, \mathrm{p}=0.10)$. However standard dosing was significantly associated with shunting towards 6-MMP (23.1\% vs 6.8\%, $p=0.008, \mathrm{OR}=4.1(1.4-12.0))$. The breakdown by drug is outlined in Figure $2 \mathrm{a}$ and $2 \mathrm{~b}$. There was a significant difference in median 6-MMP levels (1709 (0-18001) vs $\left.519(0-11001) \mathrm{pmol} / 8 \times 10^{8} \mathrm{RBC}, \mathrm{p}<0.0001\right)$ and ratio $(8.15(0-180)$ vs $3.88(0-60), p=0.0072)$ for standard dose vs low dose respectively in the combined group.

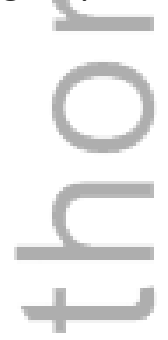

In the azathioprine alone group, standard dose patients trended towards a higher mean TGN (240.5 (0-14930) pmol/8 x 10 RBC) than low dose patients (215.5 (01189) $\left.\mathrm{pmol} / 8 \times 10^{8} \mathrm{RBC}\right)$ but this was not statistically significant $(p=0.11)$, however, 
there was a modest correlation between azathioprine dose and TGN level $(r=0.2, p=$ 0.04) (Figure 3a). There was a significant difference in median 6MMP level (495 (0$9820)$ vs $\left.1612(0-13115) \mathrm{pmol} / 8 \times 10^{8} \mathrm{RBC}, \mathrm{p}=0.0009\right)$ in the low dose compared to standard dose groups. A significant correlation was observed between $\mathrm{mg} / \mathrm{kg} / \mathrm{day}$ dose and 6MMP level $(r=0.57, p=0.001)$ (Figure $3 b)$. The rate of 6MMP shunting in patients who were on low dose azathioprine was $2.0 \%$ compared with $19.6 \%$ in those on standard dose azathioprine (OR 12.0, $(1.49-96.57))(p=0.005)$. Correlation between $\mathrm{mg} / \mathrm{kg} /$ day dose and ratio is shown in Figure 3c.

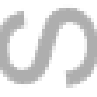

In the mercaptopurine group, there was no difference between standard dose and low dose patients in median TGN (275.0 (154.0-435.0) vs $235.0(0-1596) \mathrm{pmol} / 8 \mathrm{x}$ $\left.10^{8} \mathrm{RBC}, \mathrm{p}=0.24\right)$, nor was there a correlation between mercaptopurine dose and TGN levels ( $R=0.03, p=0.9)$ (Figure 4a). There was however a significant difference in 6-MMP levels (9399 (1700-18001) vs $\left.699(0-11001) \mathrm{pmol} / 8 \times 10^{8} \mathrm{RBC}, \mathrm{p}=0.0009\right)$ and median ratio (25 (3.91-108.0) vs $4.4(0-60.0), p=0.02)$ for standard dose compared with low dose mercaptopurine patients respectively. Correlation is shown in (Figure 4b). For mercaptopurine therapy, a trend toward shunting was seen with $17.4 \%$ on low dose versus $44.4 \%$ on standard dose therapy preferentially shunting to 6MMP (OR 3.8 (0.69-20.82) ( $p=0.18)$. A significant correlation between $\mathrm{mg} / \mathrm{kg} / \mathrm{day}$ dose and ratio is shown in (Figure 4c).

This article is protected by copyright. All rights reserved. 


\section{Adverse events}

The most common side effects encountered were cytopaenias, abnormal liver function tests or a combination of both. (Table 2) The number of patients with side effects was small as this was a cohort of patients who had been established on therapy for some time. No significant difference was found in metabolite levels between the groups of patients with adverse effects and those without.

Change in therapy

Therapy was changed as a result of testing in 116 (68\%) patients. Table 3 outlines rates of change in therapy by test indication. Of the patients who were tested due to active disease, 59 (51\%) had sub-therapeutic levels. Of those 59 patients, 51 (86\%) had a change in therapy. This was a significant difference compared with patients who had normal range TGN of whom $14 \%$ had a change in therapy $(p<0.0001)$. Of the patients tested due to another indication, there were similar rates of change in therapy in those with therapeutic and sub-therapeutic levels (62\% vs $57 \% p=1.0$ ).

(Figure 1a and 1b)

Of all the patients who had sub-therapeutic levels regardless of test indication, 74 $(84 \%)$ had a change in therapy - of those 14 (19\%) were 6MMP shunters, and $86 \%$ of those commenced allopurinol. 
In comparison, 42 (53\%) of patients who had therapeutic or supratherapeutic levels (regardless of test indication), had a change in therapy. In this group there were 11 (14\%) 6MMP shunters, of whom 7 (63\%) had a change in therapy.

Of the patients who were found to be 6MMP shunters, 14 (56\%) had subtherapeutic levels. Overall $88 \%$ of the $6 \mathrm{MMP}$ shunters had a change in therapy.

A total of 52 patients had repeat testing. Of the patients who were found to be 6MMP shunters, $12(62 \%)$ had repeat testing, and 7 (28\%) subsequently achieved therapeutic TGN levels. Of the patients who had standard thiopurine metabolism who had repeat testing performed, 12 had a dose change after being found to have sub-therapeutic levels. The mean TGN pre dose change was $120.4 \mathrm{pmol} / 8 \times 10^{8} \mathrm{RBC}$, and $185 \mathrm{pmol} / 8 \times 10^{8} \mathrm{RBC}$ post dose change. The difference was not statistically significant $(p=0.31)$. Rates of thiopurine metabolism favouring 6MMP shunting between the first and second dose did not did not significantly change in this cohort (7\% vs $16 \%, p=0.46)$.

There were three patients that had repeat testing due to an adverse effect, one of whom was found to have thiopurine metabolism favouring 6MMP shunting and allopurinol was added, one was found to have therapeutic levels and the drug was stopped and the third was found to be a shunter and no action had been taken at the time of analysis.

This article is protected by copyright. All rights reserved. 
Allopurinol patients

(1)

Allopurinol was used in $6 \%$ prior to, and $12 \%$ after, metabolite testing. Adding in allopurinol involved switching to low dose thiopurine ( $25 \%$ of the dose) in combination with $100 \mathrm{mg}$ of allopurinol. In 6MMP shunting patients, testing after allopurinol showed reversal of this in 93\% and a reduction in 6-MMP in 93\% (p $<0.005$ ) (Figure $5 a$ and 5b). There were no significant changes in TGN levels with the addition of allopurinol (4c). The mean dose of azathioprine was $2.1 \mathrm{mg} / \mathrm{kg} /$ day prior to the addition of allopurinol and $0.4 \mathrm{mg} / \mathrm{kg} /$ day after. For mercaptopurine the mean dose was $1.63 \mathrm{mg} / \mathrm{kg} /$ day pre allopurinol and $0.85 \mathrm{mg} / \mathrm{kg} /$ day post addition.

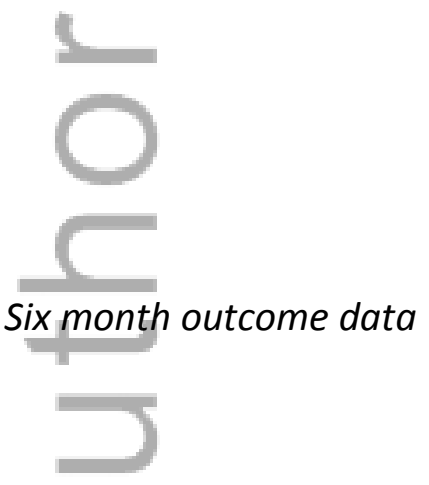

Overall, 6 month outcome data was available on 116 (69\%) of patients. At the time of testing $20(17 \%)$ of these patients were in remission. At six months, 42 (36\%) were 
in remission. Outcomes based on test indication and drug levels are outlined in Figure $6 a$ and Figure $6 b$.

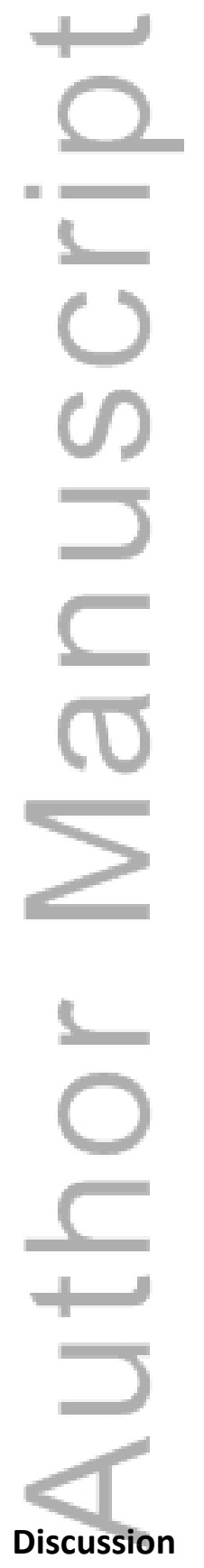

This article is protected by copyright. All rights reserved. 
With thiopurine toxicity found in approximately $25 \%$ of patients and a lack of efficacy seen in up to $70 \%^{24,25}$, thiopurine metabolite testing may provide information to optimize therapy.

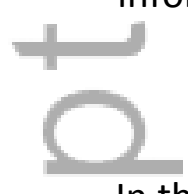

In this real world cohort, the commonest thiopurine metabolite test finding was subtherapeutic TGN levels regardless of the drug used, achievement of weight based dosing or indication for testing. $53 \%$ of patients with active disease had subtherapeutic levels while $47 \%$ had therapeutic or supratherapeutic and therefore were likely refractory to thiopurines. These findings are similar to what is reflected in the published literature to date ${ }^{26}$. This suggests that the current approach to dosing thiopurines has limitations and there is room to optimize the current strategy.

Interestingly, standard weight based dosing when compared to low dosing did not increase the proportion of patients with therapeutic TGN levels but did correlate with increased 6-MMP levels and a increased 6MMP:TGN ratio. This suggests there is a shift in the metabolic pathway favouring production of $6 M M P$ as the dose of thiopurine is increased. It has been consistently recognised that therapeutic TGN levels inversely correlate with disease activity. ${ }^{27,28}$ Our findings therefore highlight the importance of considering 
therapeutic drug monitoring in addition to standard weight based dosing, in order to ensure adequate levels. This cross sectional study finding needs to be confirmed by serial measurements using dose escalation in individual patients.

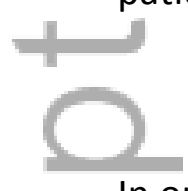

In our cohort, therapeutic drug monitoring resulted in changes in therapy most commonly in the patient group with a combination of active disease and sub-therapeutic metabolite levels. This suggests that in patients with active disease, thiopurine metabolite testing is an important step in determining whether therapy needs to be optimized or if patients are refractory to appropriately dosed drug and therefore require a change in therapy. These findings have been corroborated by two recent studies assessing the utility of thiopurine metabolite testing ${ }^{20,29}$

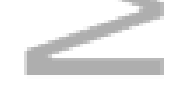

The most common change in therapy in patients with active disease and subtherapeutic levels was a change in drug dose (82\%). However in patients tested due to active disease who were found to have normal drug levels, dose change still occurred in $48 \%$ of patients. This suggests that even in the presence of normal metabolite levels, testing still provides important information for guiding practice in the presence of active disease.

This article is protected by copyright. All rights reserved. 
On repeat testing of patients who had dose escalation, there was no significant difference in TGN levels, suggesting either inadequate dose increase, non-adherence with dose escalation or the development of shunting towards 6MMP. A protocol where repeat testing is routinely $-$ performed may guide dose escalation and detect more episodes of shunting to allow the introduction of allopurinol to optimize therapy. Given that it 1 takes two weeks to achieve a steady state after a change in thiopurine dose ${ }^{30}$, checking metabolites one month following induction or dose change might be a suitable approach.

The addition of allopurinol to patients who were shunters had a favourable effect on 6-MMP levels and subsequently the ratio in the majority of cases but did not change TGN levels contrary to what has been reported in the literature ${ }^{31}$. The lack of change in TGN in this scenario may be accounted for by the conservative approach to dosing with the addition of allopurinol, particularly in the azathioprine group where $25 \%$ of the dose was the typical strategy. The trend in dosing in the mercaptopurine group is likely due to small sample size.

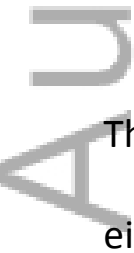

The majority of patients in this study were on concomitant therapy with either a 5-ASA and / or a biologic. Concomitant therapy with 5-ASA plays a 
role in reversing shunting ${ }^{32}$. This should be taken into account when interpreting this data. Furthermore, as this was a study of real world clinical experience, a priori power calculation was not done. However, in a post hoc analysis, power in this study was adequate for a $>90 \%$ chance that our

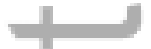

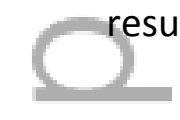

esults reflected a real trend rather than being an incidental finding.

=

No difference in the six month clinical outcome was observed based on test indication and drug levels. This is most likely due to small sample size available for measurement of six month outcomes and the lack of increase the number of patients with therapeutic levels despite dose alteration.

Additionally, this was likely contributed to by the fact that this outcome measure was based on physician global assessment rather than more concrete outcome measures such as endoscopic assessment.

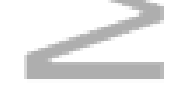

The limitations of this study are its retrospective nature, lack of standardized indication for testing and subsequent changes to management, and the fact that data on outcome was based on clinical assessment. Additionally, there were a small number of patients recruited into this study who had been taking a thiopurine for four weeks, this may not allow sufficient time to develop a clinical response. However, this represents current clinical practice. 
In conclusion, the majority of patients in this cohort had subtherapeutic TGN

levels, regardless of achieving weight based dosing. Thiopurine metabolite

testing was most useful in patients with active disease leading to a change in

management. Increasing the thiopurine dose may not achieve TGN levels in

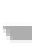

all patients, as the metabolism appears to shunt towards 6MMP as the dose

is increased. These patients may benefit from allopurinol to achieve

therapeutic TGN and prevent toxicity from high 6MMP levels, however this

needs to be assessed in a prospective study.

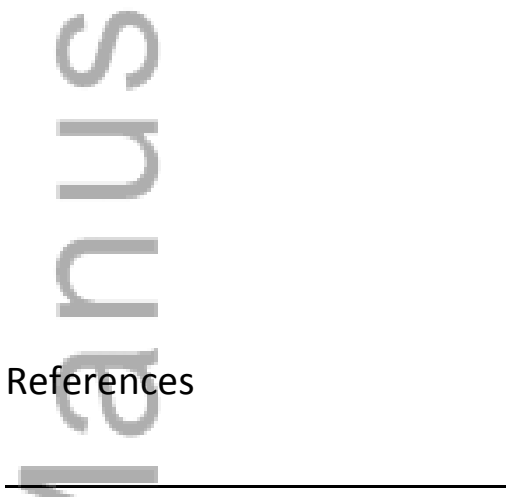

${ }^{1}$ Gearry R, Barclay M, Burt M, Collett J, Chapman B. Thiopurine drug adverse effects in a population of New Zealand patients with inflammatory bowel disease. Pharmacoepidemiol. Drug Saf. 2004; 13: 563-7.

2 Colombel JF, Sandborn WJ, Reinisch W, Mantzaris GJ, Kornbluth A, Rachmilewitz D, et al. Infliximab, azathioprine, or combination therapy for Crohn's disease. New England Journal of Medicine. 2010;362(15):1383-95. 3 Willoughby JMT, Kumar PJ, Beckett J, Dawson AM. Controlled trial of azathioprine in Crohn's disease. Lancet 1971;731:944-947

${ }^{4}$ Rosenberg JL, Levin B, Wall AJ, Kirsner JB. A controlled trial of azathioprine in the management of Crohn's disease. Dig Dis 1975;20:721-726.

${ }^{5}$ Rosenberg JL, Wall AJ, Levin B, Binder HJ, Kirsner JB. A controlled trial of azathioprine in the management of ulcerative colitis. Gastroenterology 1975;69:96-99.

${ }^{6}$ Dassopoulos T, Dubinsky MC. Randomised clinical trial: individualised vs. weight-based dosing of azathioprine in Crohn's disease. Aliment Pharmacol Ther. 2013 Nov 17.

This article is protected by copyright. All rights reserved. 
${ }^{7}$ Cosnes et al. Early administration of azathioprine vs conventional management of Crohn's Disease: a randomized controlled trial. Gastroenterology. 2013 Oct;145(4):758-65

${ }^{8}$ Dubinsky MC, Lamothe S, Yang YH, Targan SR, Sinnett D, Theoret Y, et al. Pharmacogenomics and metabolite measurement of 6-Mercaptopurine therapy in inflammatory bowel disease. Gastroenterology. 2000 Apr;118(4):705-13.

${ }^{9}$ Moreu AC. Association between 6-thioguanine nucleotides levels and clinical remission in inflammatory disease: a meta-analysis. Inflamm Bowel Dis. 2014 Mar;20(3):464-71.

10 Khan KJ. Efficacy of immunosuppressive therapy for inflammatory bowel disease: a systematic review and meta- analysis. Am J Gastroenterol 2011;106:630-42

11 Timmer A. Azathioprine and 6- mercaptopurine for maintenance of remission in ulcerative colitis. Cochrane Database Syst Rev 2012;9:Cd000478.

12 Elion GB. The George Hitchings and Gertrude Elion Lecture. The pharmacology of azathioprine. Ann. NY Acad. Sci. 1993; 685: 400-7.

13 Aarbakke J. Thiopurine biology and pharmacology. Trends Pharmacol Sci. 1997 Jan;18(1):3-7.

14 Krynetski EY. Pharmacogenetics of cancer therapy: getting personal. Am J Hum Genet. 1998 Jul;63(1):11-6.

15 Dubinsky M, Vasiliauskas EDD, Singh HDD et al. 6- thioguanine can cause serious liver injury in inflammatory bowel disease patients. Gastroenterology 2003; 125: 298-303

16 Barrett, G. Initiating Azathioprine for Crohn's Disease. Clinical

Gastroenterology and Hepatology. 2012;10:460-465

17 Blaker PA. Mechanism of allopurinol induced TPMT inhibition. Biochem Pharmacol. 2013 Aug 15;86(4):539-47.

18 Sparrow, M et al. Allopurinol safely and effectively optimizes tioguanine metabolites in inflammatory bowel disease patients not responding to azathioprine and Mercaptopurine. Aliment Pharmacol Ther 22, 441-446 19 Sparrow, M. Effect of Allopurinol on Clinical Outcomes in Inflammatory Bowel Disease Nonresponders to Azathioprine or 6-Mercaptopurine. Clinical Gastroenterology and Hepatology. 2007; 5: 209-214

20 Dubinsky, MC. A Cost-Effectiveness Analysis of Alternative Disease Management Strategies in Patients with Crohn's Disease Treated with Azathioprine or 6-Mercaptopurine. Am J Gastroenterol 2005;100:2239-2247

${ }^{21}$ Roblin, X. Use of Thiopurine Testing in the Management of Inflammatory Bowel Diseases in Clinical Practice: A Worldwide Survey of Experts. Inflamm Bowel Dis 2011;17:12.

22 Clin. Chem. 44 (1998) 551

${ }^{23}$ Dubinsky M. Azathioprine, 6-Mercaptopurine in inflammatory bowel disease: Pharmacology, efficacy, and safety. Clinical Gastroenterology and Hepatology. 2004; 2 (9); 731-743. 
${ }^{24}$ Chouchana L, Narjoz C, Beaune P, Loriot MA, Roblin X

Review article: the benefits of pharmacogenetics for improving thiopurine therapy in inflammatory bowel disease.

Aliment Pharmacol Ther. 2012 Jan; 35(1):15-36.

25 de Boer NK, van Bodegraven AA, Jharap B, de Graaf P, Mulder CJ

Review Drug Insight: pharmacology and toxicity of thiopurine therapy in patients with IBD. Nat Clin Pract Gastroenterol Hepatol. 2007 Dec; 4(12):686-94.

${ }^{26}$ Haines ML et al. Clinical usefulness of therapeutic drug monitoring of thiopurines in patients with inadequately controlled inflammatory bowel disease. Inflamm Bowel Dis. 2011 Jun;17(6):1301-7.

${ }^{27}$ Moreau AC, Laporte S, Del Tedesco E et al. (2013) Association between thiopurines metabolites levels and clinical remission in IBD patients: an updated meta-analysis. Gastroenterology 144, S-92.

${ }^{28}$ Osterman MT, Kundu R, Lichtenstein GR, Lewis JD. Association of 6-

thioguanine nucleotide levels and inflammatory bowel disease activity: a metaanalysis. Gastroenterology. 2006 Apr;130 :1047-53.

${ }^{29}$ Kennedy NA, Asser TL, Mountifield RE, Doogue MP, Andrews JM, Bampton PA (2013) Thiopurine metabolite measurement leads to changes in management of inflammatory bowel disease. Intern Med J 43, 278-286.

${ }^{30}$ Hindorf U, Lindqvist M, Peterson C, et al. (2006) Pharmacogenetics during standardised initiation of thiopurine treatment in inflammatory bowel disease.

Gut 55, 1423-31.

31 Smith MA, Blaker P, Marinaki AM, Anderson SH, Irving PM, Sanderson JD. Optimising outcome on thiopurines in inflammatory bowel disease by coprescription of allopurinol. J Crohns Colitis. 2012 Oct;6(9):905-12

32 de Graaf P1, de Boer NK, Wong DR et al. Influence of 5-aminosalicylic acid on 6-thioguanosine phosphate metabolite levels: a prospective study in patients under steady thiopurine therapy. Br J Pharmacol. 2010 Jul;160(5):1083-91

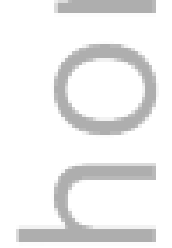

Table 1 - Median metabolite levels and rates of shunting by indication

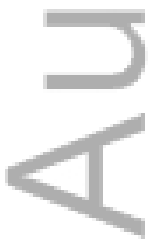

This article is protected by copyright. All rights reserved. 


\begin{tabular}{|c|c|c|c|c|c|}
\hline Indication & $\begin{array}{l}\text { Number of } \\
\text { patients } \\
\text { (\%) }\end{array}$ & $\begin{array}{l}\text { Median } \\
\text { 6-TGN } \\
\text { (range) }\end{array}$ & $\begin{array}{l}\text { Median } \\
\text { 6-MMP } \\
\text { (range) }\end{array}$ & $\begin{array}{l}\text { Number of } \\
\text { patients } \\
\text { sub- } \\
\text { therapeutic } \\
\text { (\%) }\end{array}$ & $\begin{array}{l}\text { 6MMP } \\
\text { Shunters } \\
(\%)\end{array}$ \\
\hline Active Disease & $135(80)$ & $232(0-1596)$ & $\begin{array}{l}1293 \\
(0- \\
16623)\end{array}$ & $70(53)$ & $20(15)$ \\
\hline Adverse Effect & $17(10)$ & $\begin{array}{l}287(109- \\
1596)\end{array}$ & $\begin{array}{l}1052 \\
(0- \\
18000) \\
\end{array}$ & $4(22)$ & $3(18)$ \\
\hline $\begin{array}{l}\text { Check } \\
\text { Compliance }\end{array}$ & $13(8)$ & $169(0-832)$ & $\begin{array}{l}961(38- \\
12000)\end{array}$ & $7(58)$ & $3(23)$ \\
\hline Other & $4(2)$ & $349(0-564)$ & $\begin{array}{l}1506 \\
(69- \\
3392)\end{array}$ & $4(57)$ & $0(0)$ \\
\hline Total & 169 & & & 85 & 26 \\
\hline
\end{tabular}

This article is protected by copyright. All rights reserved. 
Table 2 - Adverse effects and metabolite levels

\begin{tabular}{|c|c|c|c|}
\hline Adverse Effect & $\begin{array}{l}\text { Number } \\
\text { of } \\
\text { Patients } \\
\text { (\%) }\end{array}$ & $\begin{array}{l}\text { Median } \\
\text { 6TGN } \\
\text { (range) }\end{array}$ & $\begin{array}{l}\text { Median } \\
\text { 6MMP } \\
\text { (range) }\end{array}$ \\
\hline Cytopenia & $5(3)$ & $\begin{array}{l}435 \\
(186- \\
1596) \\
\end{array}$ & $\begin{array}{l}1700 \\
(361- \\
4779) \\
\end{array}$ \\
\hline Abnormal LFTs & $4(2)$ & $\begin{array}{l}321 \\
(155- \\
600) \\
\end{array}$ & $\begin{array}{l}3679 \\
(246- \\
9723) \\
\end{array}$ \\
\hline $\begin{array}{l}\text { Combination of Cytopenia } \\
\text { and Abnormal LFTs }\end{array}$ & $1(1)$ & $639(-)$ & $264(-)$ \\
\hline Myalgias/arthralgias/rash & $2(1)$ & $\begin{array}{l}280 \\
(273- \\
287) \\
\end{array}$ & $\begin{array}{l}350(0- \\
699)\end{array}$ \\
\hline Other & $3(2)$ & $\begin{array}{l}212 \\
(151- \\
733)\end{array}$ & $\begin{array}{l}1171 \\
(469- \\
3003)\end{array}$ \\
\hline
\end{tabular}

This article is protected by copyright. All rights reserved. 
Table 3 - Change in therapy by test indication

\begin{tabular}{|lll|lll|}
\hline & $\begin{array}{l}\text { Active } \\
\text { Disease } \\
\mathbf{N = 1 1 6}\end{array}$ & $\begin{array}{l}\text { Adverse } \\
\text { Effect } \\
\mathbf{N}=\mathbf{1 5}\end{array}$ & $\begin{array}{l}\text { Check } \\
\text { Compliance } \\
\mathbf{N = 1 0}\end{array}$ & $\mathbf{N = 3}$ & $\mathbf{N}=\mathbf{2 5}$ \\
\hline $\begin{array}{l}\text { Sub- } \\
\text { therapeutic } \\
\text { levels (\%) }\end{array}$ & $60(52)$ & $5(33)$ & $5(50)$ & $0(0)$ & $14(56)$ \\
\hline $\begin{array}{l}\text { Change in } \\
\text { management } \\
\text { (\%) }\end{array}$ & $78(67)$ & $8(53)$ & $4(40)$ & $0(0)$ & $21(84)$ \\
\hline $\begin{array}{l}\text { Change } \\
\text { Drug }\end{array}$ & $1 \%)$ & & & $0(0)$ & $1(5)$ \\
\hline $\begin{array}{l}\text { Cease Drug } \\
\text { (\%) }\end{array}$ & $6(8)$ & $2(25)$ & $0(0)$ & $0(0)$ & $3(14)$ \\
\hline $\begin{array}{l}\text { Change } \\
\text { Dose (\%) }\end{array}$ & $48(62)$ & $2(25)$ & $3(75)$ & $0(0)$ & $0(0)$ \\
\hline $\begin{array}{l}\text { Encourage } \\
\text { Compliance } \\
\text { (\%) }\end{array}$ & $7(9)$ & $0(0)$ & $0(0)$ & $0(0)$ & $0(0)$ \\
\hline $\begin{array}{l}\text { Allopurinol } \\
\text { (\%) }\end{array}$ & $1(1)$ & $1(13)$ & $0(0)$ & $0(0)$ & $17(81)$ \\
\hline
\end{tabular}

This article is protected by copyright. All rights reserved. 


\section{University Library}

\section{- M M N E R VA A gateway to Melbourne's research publications}

Minerva Access is the Institutional Repository of The University of Melbourne

\section{Author/s:}

Goldberg, R;Moore, G;Cunningham, G;Schulberg, J;Marsh, P;Brown, S;Connell, W;Lust, M;Kamm, MA;Bell, S

Title:

Thiopurine metabolite testing in inflammatory bowel disease

\section{Date:}

2016-03-01

\section{Citation:}

Goldberg, R., Moore, G., Cunningham, G., Schulberg, J., Marsh, P., Brown, S., Connell, W., Lust, M., Kamm, M. A. \& Bell, S. (2016). Thiopurine metabolite testing in inflammatory bowel disease. JOURNAL OF GASTROENTEROLOGY AND HEPATOLOGY, 31 (3), pp.553-560. https://doi.org/10.1111/jgh.13210.

Persistent Link:

http://hdl.handle.net/11343/290987 